\title{
PERANCANGAN DAN REALISASI PERANGKAT PANCAR-TERIMA FM-DIRECT SEQUENCE SPREAD SPRECTRUM PADA FREKUENSI 40 MHz
}

\author{
Andi Andriana ${ }^{1}$, Heroe Wijanto ${ }^{2}$, Budianto $^{3}$ \\ ${ }^{1}$ Divisi Core Network Engineering - PT Telekomunikasi Seluler (Telkomsel) \\ ${ }^{2}$ Program Magister Teknik Telekomunikasi - Sekolah Tinggi Teknologi Telkom, Bandung \\ ${ }^{3}$ Jurusan Teknik Elektro - Sekolah Tinggi Teknologi Telkom, Bandung \\ ${ }^{1}$ andi_andriana@telkomsel.co.id, ${ }^{2} \underline{\text { hrw @ stelkom.ac.id, }},{ }^{3}$ bud@ stttelkom.ac.id
}

\begin{abstract}
Abstrak
Penelitian ini telah menghasilkan perangkat pancar-terima FM-DSSS (Frequency Modulation - Direct Sequence Spread Spectrum). Pemancar meliputi LPF $4 \mathrm{kHz}$, proses modulasi FM Pita Sempit berlebar pita $8 \mathrm{KHz}$ pada frekuensi pembawa $40 \mathrm{MHz}$, sinyal pembawa termodulasi frekuensi mengalami penebaran ke lebar pita $2 \mathrm{MHz}$ oleh sinyal kode acak semu, daya pemancar 1,37 Watt. Sedangkan perangkat penerima FM-DSSS meliputi pre-amplifier, balance modulator, Phase Lock Loop (PLL) dan penerima FM Super-heterodyne konversi ganda pada frekuensi IF $455 \mathrm{kHz}$. Processing Gain sistem ini diperoleh sebesar 261,1 atau 24,16 dB. Dari hasil pengujian, sistem FM-DSSS ini mampu bekerja pada lingkungan jamming setelah menurunkan levelnya dengan cara menebarkan pada bandwidth cukup lebar.
\end{abstract}

Kata kunci : sistem transceiver FM-DSSS, FM Pita Sempit, PLL, penerima FM super-heterodyne

\begin{abstract}
This research has been realized a FM-DSSS (Frequency Modulation - Direct Sequence Spread Spectrum) transceiver. The transmitter consists of LPF $4 \mathrm{kHz}$, Narrow-band FM process with $8 \mathrm{kHz}$ of bandwidth on $40 \mathrm{MHz}$ of carrier frequency, frequency modulated carrier signal spreading to $2 \mathrm{MHz}$ of bandwidth due to the pseudo random code, and spread power of 1,37 Watt. On the other hand, the FM-DSSS receiver includes pre-amplifier, balance modulator, Phase Lock Loop (PLL), and double conversion Superheterodyne FM working on $455 \mathrm{kHz}$ of IF frequency. The Processing Gain of system is 261,1 or 24,16 dB. The test result shows that this FM-DSSS System is capable of working on jamming environment, where the level of jamming signal could be decreased through spreading it into a wide enough bandwidth.
\end{abstract}

Keywords: FM-DSSS transceiver system, Narrow-Band FM, PLL, super-heterodyne FM receiver

\section{Pendahuluan}

Sistem Spread Spectrum dikembangkan sejak pertengahan tahun 1950-an di bidang militer ketika dibutuhkan sistem komunikasi yang tahan terhadap interferensi dan jamming, aman dari penyadapan dan kemampuan akses jamak (multiple access). Penerapan lain teknologi spread spectrum adalah pada sistem komunikasi bergerak seluler Code Division Multiple Access (CDMA) dengan efisiensi spektral sangat tinggi.

Penilitian ini bertujuan menghasilkan perancangan dan implementasi sistem perangkat transceiver FM-DSSS (Fequency Modulation Direct Sequence Spread Spectrum). Perangkat sistem dibuat dengan spesifikasi berikut:

- lebar pita sinyal informasi $4 \mathrm{kHz}$,

- proses modulasi FM pita sempit selebar $8 \mathrm{KHz}$,

- frekuensi pembawa $40 \mathrm{MHz}$,

- sinyal FM ditebarkan ke lebar pita $2 \mathrm{MHz}$ oleh sinyal kode acak semu,

- daya pemancar 1,37 Watt,

- diskriminasi FM dengan PLL (phase lock loop),

- penerima FM Super-heterodyne konversi ganda bekerja pada frekuensi IF $455 \mathrm{kHz}$,

- Processing Gain sebesar 250 atau 24 dB.

\section{Sistem Transceiver FM-DSSS}

Spread Sprectrum adalah penebaran spektral sinyal informasi pada rentang alokasi frekuensi sangat lebar, jauh melebihi bandwidth minimum yang diperlukan. Pada sistem pemancar FM-DSSS, sinyal informasi termodulasi FM dimodulasi lagi oleh deretan kode penebar biner acak semu. Di penerima FM-DSSS, setelah proses sinkronisasi, dilakukan demodulasi FM untuk menghasilkan sinyal informasi kembali. Skematika sistem transceiver FM-DSSS ditunjukkan pada Gambar 1.

Faktor perbaikan pada sistem penerima spread spectrum disebut Processing Gain (PG), yaitu:

$$
P G=\frac{B W_{R F}}{B W_{0}}
$$

dengan $B W_{R F}$ adalah bandwidth sinyal spread spectrum yang ditransmisikan dan $B W_{0}$ adalah bandwidth sinyal informasi.

Performansi $(S / N)$ penerimaan sinyal pada lingkungan jamming $(J)$ dapat dihitungkan dari:

$$
\begin{aligned}
& \left(\frac{S}{N}\right)_{I N}(d B)=-\frac{J}{S}(d B) \\
& \left(\frac{S}{N}\right)_{\text {OUT }}(d B)=G_{P}(d B)-\frac{J}{S}(d B)
\end{aligned}
$$




\section{Realisasi Sistem Perangkat FM-DSSS}

\subsection{Perangkat Pemancar FM-DSSS}

Fungsi setiap blok pada perangkat pemancar FM-DSSS di Gambar 2, dijelaskan sebagai berikut:

a. Pre-amplifier, untuk menguatkan sinyal listrik sangat lemah yang berasal dari microphone.

b. LPF Aktif $4 \mathbf{~ k H z}$, sebagai pembatasi lebar pita sinyal informasi. LPF aktif direalisasikan untuk frekuensi cut off $4 \mathrm{kHz}$ dan redaman $25 \mathrm{~dB}$ pada $8 \mathrm{kHz}$ (orde 4) dengan IC Motorola MC1741.

c. Modulator FM 20 MHz, adalah pembangkit sinyal pembawa $20 \mathrm{MHz}$ yang juga berfungsi sebagai modulator FM pita sempit. Osilator direalisasikan dalam rangkaian Colpitts dengan transistor Motorola 2N2222A dan pengendali kristal $20 \mathrm{MHz}$, dengan modulator reaktansi melalui dioda varaktor MV2105.

d. Pelipat 2 Frekuensi, adalah penghasil sinyal pembawa $40 \mathrm{MHz}$ dari masukan sinyal $20 \mathrm{MHz}$. Rangkaian pelipat 2 frekuensi direalisasikan dengan penguat tertala dua tingkat dari transistor 2SC2026 yang memiliki $f_{T}=2 \mathrm{GHz}$.

e. Balance Modulator, merupakan mixer dari IC Motorola MC1946, sebagai spreader sinyal pembawa termodulasi FM dengan sinyal kode penebar dari $P R G$ yang telah diubah menjadi pulsa berlebar pita terbatas oleh BTF, sehingga menghasilkan sinyal FM-DSSS.

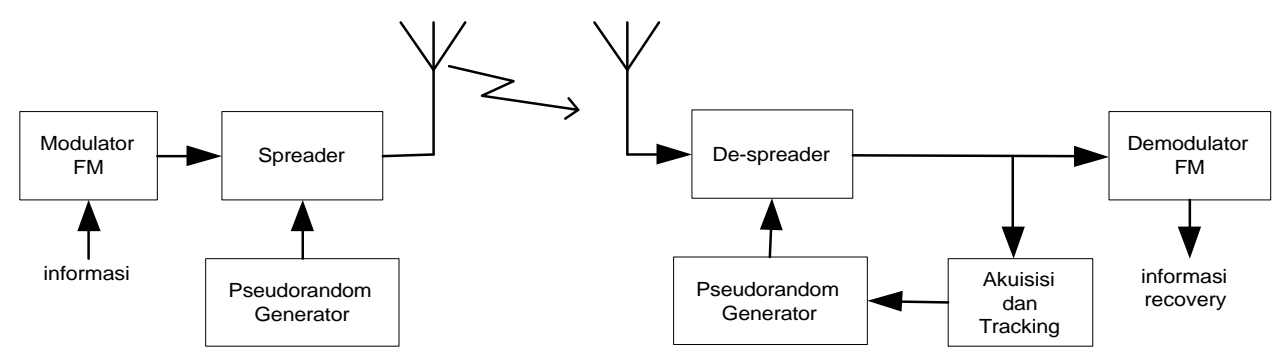

Gambar 1. Diagram Skematik Sistem FM-DSSS

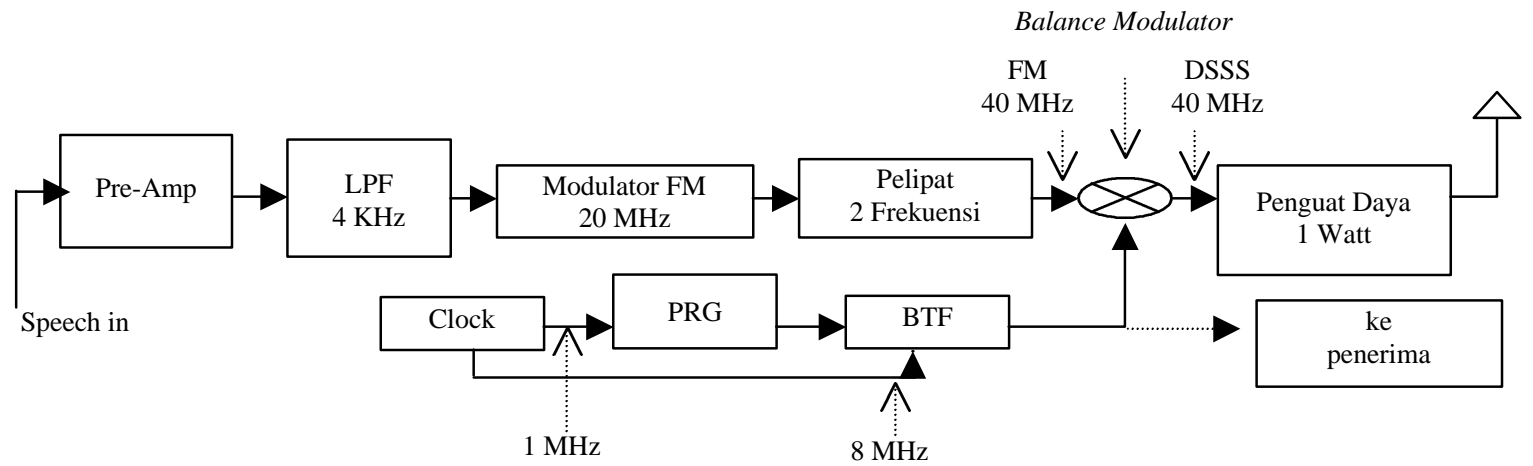

Gambar 2. Skematik Perancangan Perangkat Pemancar FM-DSSS

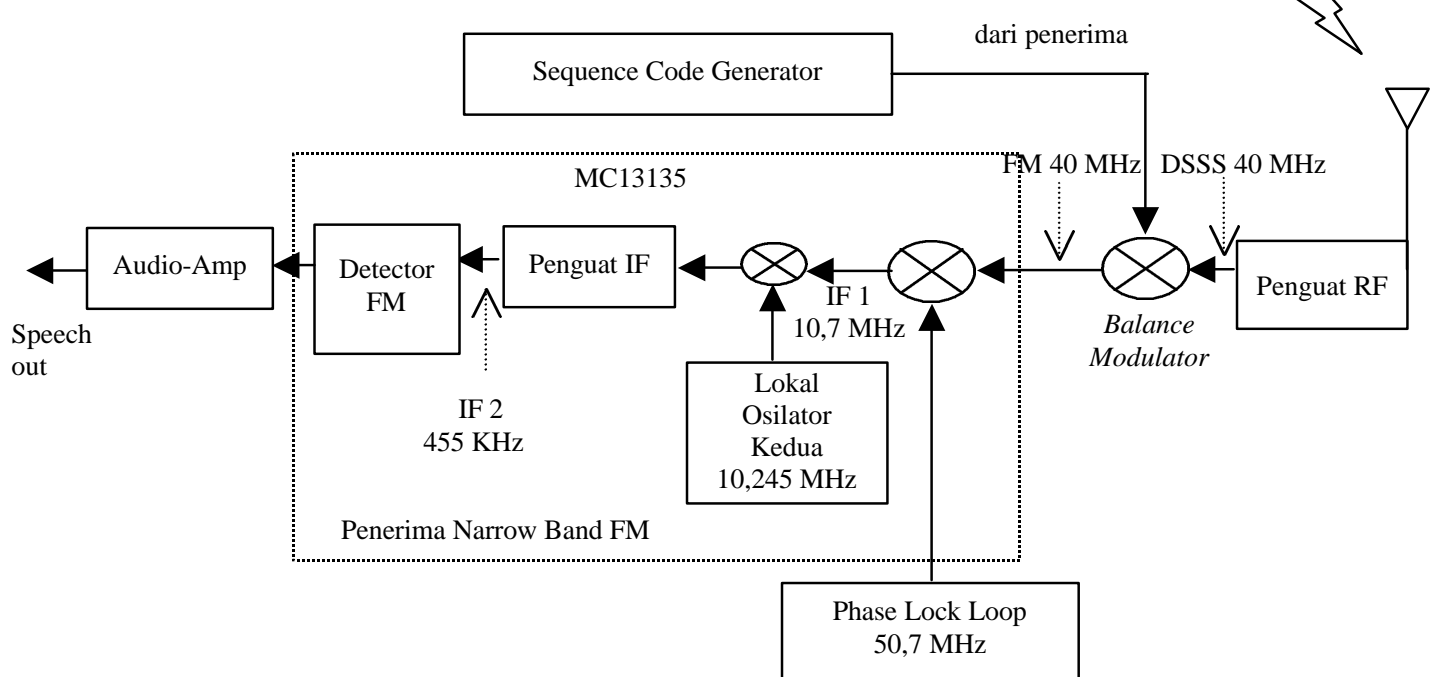

Gambar 3. Skematik Perancangan Perangkat Penerima FM-DSSS

Perancangan Dan Realisasi Perangkat Pancar-Terima FM-Direct Sequence Spread Sprectrum Pada Frekuensi $40 \mathrm{MHz}$ (Andi Andriana) 
f. Pembangkit Pulsa Detak, menghasilkan pulsa detak $1 \mathrm{MHz}$ pengendali generator kode penebar acak semu $(P R G)$ dan $8 \mathrm{MHz}$ pengendali BTF. Pembangkit pulsa detak dibangkitkan oleh kristal $16 \mathrm{MHz}$ dan gerbang NAND dari IC 74LS93.

g. PRG (Pseudorandom Noise Generator), sebagai pembangkit kode acak semu MLS dengan periode $N=2^{r}-1$ bit berkecepatan 1 Mcps, direalisasikan menurut polinomial $\left(1+X^{3}+X^{10}\right)$.

h. BTF (Binary Transfersal Filter), sebagai pembatas lebar pita sinyal kode acak semu dengan mengubah bentuk sinyal NRZ menjadi pulsa raised cosine waktu terbatas.

i. Penguat Daya, menguat sinyal FM-DSSS agar memiliki daya sinyal yang cukup untuk dipancarkan, yaitu 1,37 Watt pada frekuensi 40 $\mathrm{MHz}$, dengan lebar pita $2 \mathrm{MHz}$.

\subsection{Perangkat Penerima FM-DSSS}

Perangkat penerima FM-DSSS, seperti diperlihatkan di Gambar 3, terdiri dari beberapa bagian blok sebagai berikut:

\section{a. Penguat RF}

b. Balance Modulator, diimplementasikan dari IC Motorola MC1946 sebagai despreader sinyal FM-DSSS $40 \mathrm{MHz}$ oleh kode penebar lokal sinkron 1 Mcps untuk menghasilkan sinyal FM $40 \mathrm{MHz}$ berpita sempit $8 \mathrm{kHz}$.

c. Phase Lock Loop (PLL), merupakan osilator lokal-I yang bertugas menghasilkan sinyal pembawa lokal 50,7 MHz. VCO (Voltage Controled Oscillator) direalisasikan dengan IC MC1648 yang mampu bekerja sampai $225 \mathrm{MHz}$. Dioda varactor yang digunakan adalah MV2105 dengan kapasitansi $13,5 \mathrm{pF}-16,5 \mathrm{pF}$. Detektor Fasa dan programmable prescaler dibuat dari IC MC145166 (Dual PLL).

d. Pencampur I, berfungsi untuk menghasilkan frekuensi IF sebesar 10,7 MHz.

e. Osilator lokal II, bertugas untuk menghasilkan sinyal berfrekuensi $10,245 \mathrm{MHz}$

f. Pencampur II, berfungsi melakukan proses pencampuran sinyal keluaran pencampur I dengan osilator lokal II, sehingga dihasilkan frekuensi IF sebesar $455 \mathrm{kHz}$.

g. Penguat IF, berfungsi menguatkan sinyal frekuensi IF agar memiliki daya yang cukup untuk melakukan proses deteksi sinyal FM

h. Detektor FM, berfungsi untuk mendeteksi sinyal FM sehingga dapat diperoleh kembali sinyal informasinya. Detektor FM direalisasikan menggunakan IC MC13135 yang terdiri dari dua buah osilator lokal, dua buah pencampur, penguat IF dan detektor, serta penguat operasional dengan beberapa kelebihan berikut :

- frekuensi kerja hingga $200 \mathrm{MHz}$.

- tegangan kerja rendah, yaitu 2,0 - 6,0 VDC

- $\quad$ arus kerja kecil, yaitu 3,5 mA

i. Penguat audio, berfungsi menguatkan sinyal audio yang berfrekuensi $20 \mathrm{~Hz}-20 \mathrm{kHz}$.

\section{Pengukuran dan Evaluasi Sistem Perangkat}

\subsection{Pengukuran Perangkat Pemancar FM-DSSS}

\subsubsection{Pre-Amplifier dan LPF}

Pada frekuensi $4 \mathrm{kHz}$, Pre-Amplifier dengan level masukan 45,31 mVpp memberikan level keluaran 3,625 $\mathrm{Vpp}$, sehingga diperoleh penguatan 80 kali atau $38 \mathrm{~dB}$. Hasil pengamatan sinyal masukan dan keluaran Pre-Amplifier ditunjukan di Gambar 4.a, yang juga menunjukkan Pre-Amplifier masih bersifat linier pada penguatan $38 \mathrm{~dB}$.

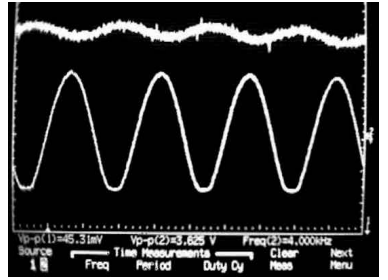

(a) Pre-Amplifier

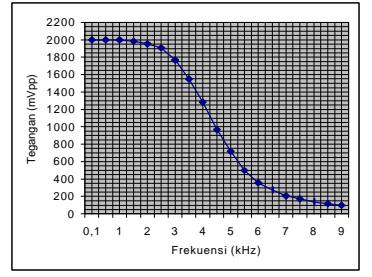

(b) Respons LPF
Gambar 4. Penguatan Pre-Amplifier dan Respons LPF

Pengukuran respons LPF $4 \mathrm{kHz}$ dilakukan dari perubahan level keluaran ketika diberikan sinyal masukan yang dijaga konstan $2 \mathrm{Vpp}$ dengan frekuensi diubah-ubah pada langkah $0,5 \mathrm{kHz}$. Respons frekuensi LPF hasil realisasi ditunjukkan pada Gambar 4.b, terlihat frekuensi cut off terjadi pada $3,83 \mathrm{kHz}$, lebih sempit $171,37 \mathrm{~Hz}$ atau $4,25 \%$ dari cut off yang diinginkan $4 \mathrm{kHz}$.

\subsubsection{Sinyal Modulasi FM}

Modulator FM diamati dengan memberi masukan sinyal pemodulasi sinusoidal $4 \mathrm{kHz}$. Gambar 5.a menunjukan bahwa kondisi carrier null terjadi pada amplituda sinyal pemodulasi $12,5 \mathrm{Vpp}$, sehingga diperoleh angka sensitivitas modulator FM: $K_{f}=\beta_{0} f_{m} / A_{m}=2,4 \times 4 \mathrm{kHz} /(1 / 212,5 \mathrm{~V})=1,536 \mathrm{kHz} / \mathrm{V}$.

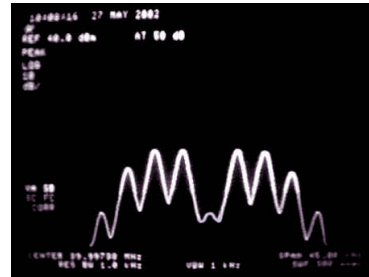

(a) Carrier Null 12,5 Vpp

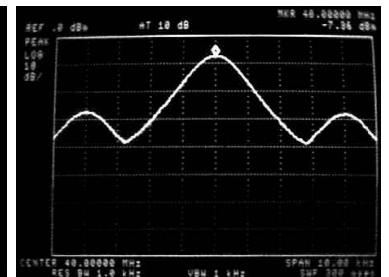

(b) Amplitudo 2,672 Vpp
Gambar 5. Spektral sinyal FM dengan input $4 \mathrm{kHz}$

Di Gambar 5.b ditunjukkan hasil pengamatan untuk masukan modulator berupa sinyal pemodulasi sinusoidal $4 \mathrm{kHz}$ beramplituda 2,672 Vpp, yang memperlihatkan lebar pita spektral sinyal FM 8 kHz.

\subsubsection{Pengujian PRG dan BTF}

Keluaran PRG 1 Mcps diperlihatkan pada Gambar 6.a, bagian atas sebelum difilter dan bagian 
bawah sesudah difilter oleh BTF. Rangkaian PRG menggunakan shift register 10 tingkat, sehingga diperoleh periode acak-semu $2^{10}-1=1023$ chip . Gambar 6.b memperlihatkan pola mata keluaran BTF dimana tampak sinyal NRZ keluaran PRG telah diubah ke bentuk pulsa raised cosine waktu terbatas.

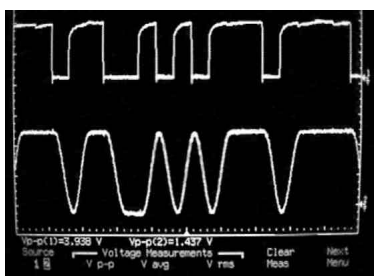

(a) Deretan Pulsa

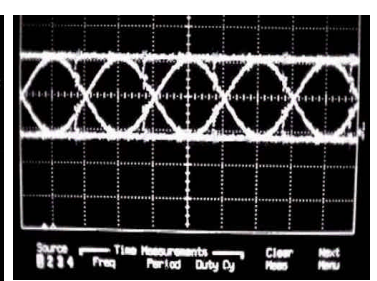

(b) Pola Mata
Gambar 5. Sinyal kode penebar acak-semu 1 Mcps

\subsubsection{Speader dan Sinyal FM-DSSS}

Pengujian karakteristik balance modulator sebagai spreader dilakukan dengan memberikan sinyal sinusoidal $1 \mathrm{MHz}$ dan sinyal $40 \mathrm{MHz}$ dari modulator FM pada kedua masukannya. Pada Gambar 6.a diketahui level suppressed carrier terhadap terhadap pita sisinya adalah $-30 \mathrm{~dB}$, dengan kedua sisinya yang balance tak-sempurna.

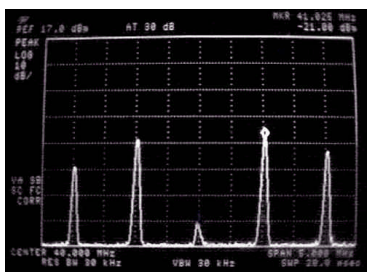

(a) Balance Modulator

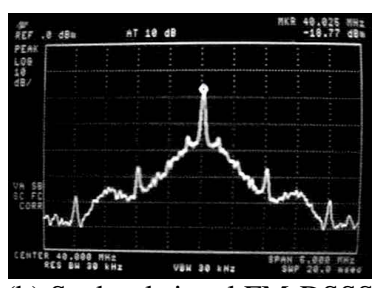

(b) Spektral sinyal FM-DSSS
Gambar 6. Proses Spreading (span $5 \mathrm{MHz}$ )

Gambar 6.b menunjukan spektral sinyal FMDSSS keluaran balance modulator sebagai spreader yang sangat dominan menghasilkan main lobe. Ini berarti BTF sebagai pembentuk pulsa raised cosine bekerja sesuai rancangan. Sinyal FM-DSSS selebar dua kali chip rate PRG 1 Mcps, yaitu $2 \mathrm{MHz}$.

\subsubsection{Penguat Daya}

Pengujian dilakukan dengan menghubungkan seluruh tingkat penguat daya sekaligus, sehingga terukur daya pancar melalui Osiloskop, seperti terlihat pada Gambar 7.a. Penguat daya dapat memberikan penguatan yang masih linear pada keluaran 1,37 Watt.

\subsection{Pengukuran Perangkat Penerima FM-DSSS}

\subsubsection{Penguat RF}

Pengujian pada frekuensi $40 \mathrm{MHz}$ menunjukkan bahwa Penguat Daya pada penerima memberikan level keluaran 1,578 Vpp ketika diberi masukan pada level 14,06 $\mathrm{mVpp}$, sehingga dapat dihitung penguatannya sebesar 112,23 atau $41 \mathrm{~dB}$, sepeti terlihat pada Gambar 7.b.

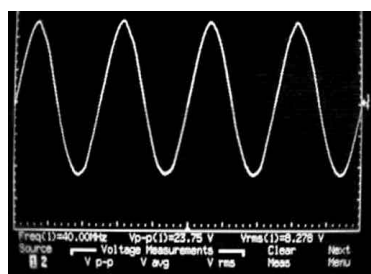

(a) Uji Penguat Daya (Tx)

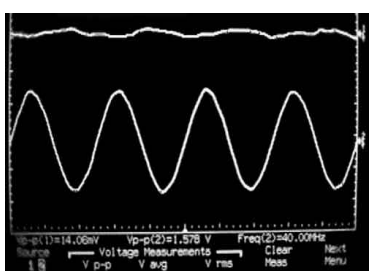

(b) Uji Penguat RF (Rx)
Gambar 7. Penguat Daya (Tx) dan Penguat RF (Rx)

\subsubsection{Despreading dan Down Converting}

Pada Gambar 8.a terlihat hasil despreading pada level $-3,59 \mathrm{dBm}$ dengan masih terdapatnya spektral sinyal kode penebar pada sisi-sisi spektral sinyal FM pita sempit. Hal ini merupakan akibat kurang sempurnanya sinkronisasi kode penebar pada sinyal FM-DSSS yang diterima dengan deretan kode penebar lokal di penerima.

PLL sebagai sumber pembawa lokal I dibangun dari osilator kristal 14,31818 $\mathrm{MHz}$ yang cukup stabil, kemudian dilakukan pembagian 2048 (internal IC MC145166) untuk menghasilkan frekuensi referensi $6,9 \mathrm{kHz}$. Pada Gambar 8.b terlihat keluaran VCO pada level 3,08 dBm. Keluaran VCO ini telah menunjukan sinyal keluaran PLL yang sudah terkunci stabil pada 50,7 MHz.

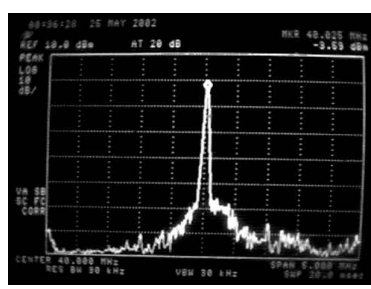

(a) FM Pita Sempit $40 \mathrm{MHz}$ (span $5 \mathrm{MHz}$ )

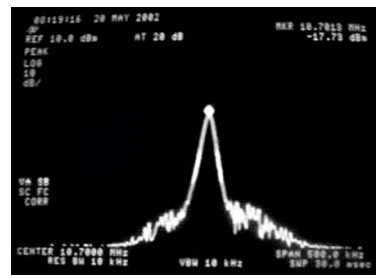

(c) FM Pita Sempit $10,7 \mathrm{MHz}$ Down Converting I (span $500 \mathrm{kHz}$ ) Hasil Despreading

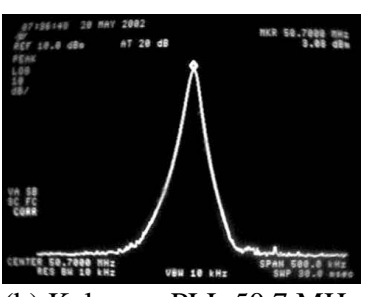

(b) Keluaran PLL 50,7 MHz sebagai Pembawa Lokal I (span $500 \mathrm{kHz}$ )

(d) FM Pita Sempit $455 \mathrm{kHz}$ Down Converting II (info $4 \mathrm{kHz}$ ) (span $500 \mathrm{kHz})$

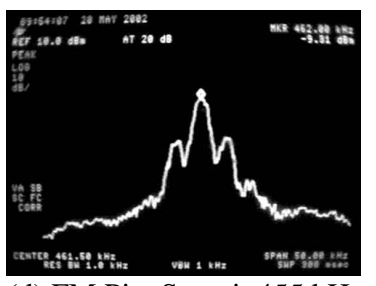

Gambar 8. Hasil Depreading dan Down Converting

Pada Gambar 8.c terlihat bahwa keluaran Mixer-I adalah 10,7 MHz dengan level -17,73 dBm, yang merupakan selisih frekuensi sinyal FM-DSSS $40 \mathrm{MHz}$ dengan osilator lokal-I 50,7 MHz. Di Gambar 8.d diperlihatkan bahwa Mixer-II pada 455 $\mathrm{kHz}$ dengan level $-12,91 \mathrm{dBm}$, yang merupakan selisih frekuensi keluaran Mixer-II 10,7 MHz dengan osilator lokal-II 10,245 $\mathrm{MHz}$, kaetika diberikan sinyal pemodulasi $4 \mathrm{kHz}$. 


\subsection{Performansi di Lingkungan Jamming}

\subsubsection{Hasil Despreading Terganggu Jamming}

Untuk mensimulasikan lingkungan jamming, dipancarkan sinyal sinusoidal $40 \mathrm{MHz}$ dari suatu generator bertegangan 2,063 Vpp pada jarak $25 \mathrm{~cm}$ dari penerima FM-DSSS. Pengamatan dilakukan ketika sinyal FM-DSSS dengan informasi $4 \mathrm{kHz}$ dipancarkan pada jarak 1 meter dari penerima.

Gambar 9.a dan 9.b menunjukkan perbedaan antara sinyal hasil despreading tanpa dan dengan jamming. Pada Gambar 9.b terlihat sinyal jamming ditebarkan oleh kode penebar lokal pada bandwidth selebar $2 \mathrm{MHz}$ dengan level $-65,5 \mathrm{dBm}$, sementara level sinyal hasil despreading $-29,1 \mathrm{dBm}$.

Secara perhitungan, pemancaran sinyal FMDSSS $40 \mathrm{Mhz}$ dengan daya $1,37 \mathrm{~W}$ atau $31,36 \mathrm{dBm}$, dengan semua feeder dan antena diabaikan, dalam jarak 1 meter terjadi redaman ruang bebas $4,49 \mathrm{~dB}$, sehingga diperoleh level daya terima $S=26,87 \mathrm{dBm}$. Sedangkan sumber jamming $40 \mathrm{MHz}$ bertegangan $2,063 \mathrm{Vpp}$ yang memancar pada beban $50 \Omega$, pada jarak $25 \mathrm{~cm}$ ke penerima menyebabkan level jamming $J=18,98 \mathrm{dBm}$. Dari Persamaan (2) diperoleh kualitas sinyal input $(S / N)_{\mathrm{IN}}=7,89 \mathrm{~dB}$. Dengan Processing Gain PG $=261,1=24,16 \mathrm{~dB}$, dari Persamaan (3) diperoleh kualitas sinyal setelah despreading di penerima $(S / N)_{\mathrm{OUT}}=32,05 \mathrm{~dB}$.

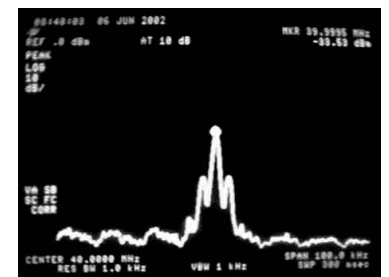

(a) FM Pita Sempit $40 \mathrm{MHz}$ despresding tanpa jamming (info $4 \mathrm{kHz}$ ) (span $5 \mathrm{MHz})$

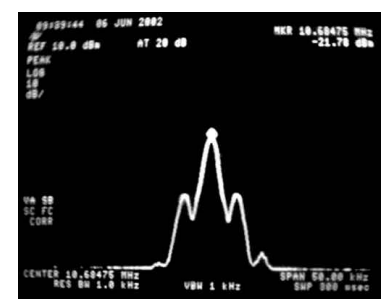

(c) FM Pita Sempit $10,7 \mathrm{MHz}$ non-DSSS tanpa jamming (info $4 \mathrm{kHz}$ ) (span $50 \mathrm{kHz})$

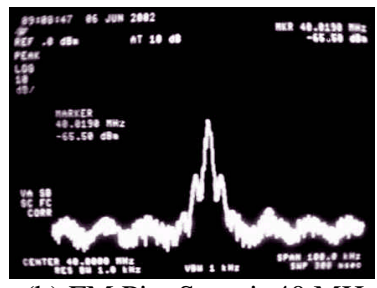

(b) FM Pita Sempit $40 \mathrm{MHz}$ despreading dengan jamming (info $4 \mathrm{kHz}$ ) (span $5 \mathrm{MHz}$ )

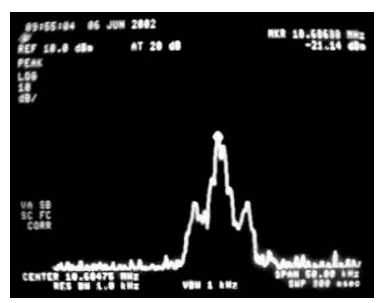

(d) FM Pita Sempit 10,7MHz non-DSSS dengan jamming (info $4 \mathrm{kHz}$ ) (span $50 \mathrm{kHz}$ )
Gambar 9. Performansi pada Lingkungan Jamming

\subsubsection{Gangguan Jamming pada Sistem Non-DSSS}

Pada pengamatan ini, sinyal informasi $4 \mathrm{kHz}$ dimodulasi FM kemudian langsung dikuatkan dengan daya 1,37 Watt, tanpa lebih dulu dilakukan spreading, sehingga bandwidth transmisi tetap selebar $8 \mathrm{kHz}$ (FM pita sempit). Pemancar juga ditempatkan pada jarak $1 \mathrm{~m}$ dari penerima FM tanpa despreading, dan sinyal jamming berjarak $25 \mathrm{~cm}$ dari penerima dengan level 2,063 Vpp. Sinyal terima ini diamati pada IF 10,7 dalam span $50 \mathrm{kHz}$.

Dari Gambar 9.c terlihat bahwa sinyal IF tanpa jamming diterima baik pada level $-21,78 \mathrm{dBm}$. Sedangkan pada Gambar 9.d terlihat bahwa sinyal IF FM dengan jamming telah mengalami cacat akibat oleh level jamming yang cukup mengganggu.

\section{Kesimpulan}

Dari pengujian terhadap hasil realisasi sistem transceiver FM-DSSS, diambil kesimpulan bahwa Sinyal FM pita sempit $7,7 \mathrm{kHz}$ telah dapat ditebarkan oleh sinyal PRG 1 Mcps ke rentang bandwidth $2 \mathrm{MHz}$ pada frekuensi $40 \mathrm{MHz}$, sehingga diperoleh $\mathrm{PG}=261,1$ atau $24,16 \mathrm{~dB}$. Terjadi ketidaksempurnaan proses despreading yang disebabkan oleh delay transmisi. Semakin besar Processing Gain, performansi sinyal terima semakin baik. Sinyal jamming pada penerima FM-DSSS akan ditebarkan pada bandwidth yang sangat lebar, sehingga turun levelnya turun hingga tidak mengganggu penerimaan sinyal informasi. S/N input penerima sebesar $7,89 \mathrm{~dB}$, sedangkan $\mathrm{S} / \mathrm{N}$ output penerima diperoleh $32,05 \mathrm{~dB}$.

Hendaknya sistem dilengkapi dengan proses sinkronisasi (akuisisi dan tracking), sehingga dihasilkan penerimaan sinyal berkualitas baik. Balance modulator sebagai spreader sinyal FM dengan kode penebar hendaknya dibuat hingga suppressed carrier serendah mungkin dan kedua sisinya balance hampir sempurna.

\section{Daftar Pustaka}

[1] Boylestad, R. and L. Nashelsky, Electronic Devices and Circuit Theory. Prentice Hall.

[2] Cooper, G. R. and C. D. McGillem. 1986. Modern Communication and Spread Spectrum, Singapore: MacGraw-Hill.

[3] Dixon, R. C. 1994. Spread Spectrum Systems with Commercial Applications. $3^{\text {rd }}$ Ed. New York: Jhon Wiley and Sons, Inc.

[4] Doberstein, D. 1996. A 16 KBS Full Duplex Spread Spectrum Receiver RF Data Link. President DKD Instruments.

[5] Meel, J. Introduction Spread Spectrum. Rotselaar, Belgium: Sirius Communications.

[6] Peterson, R.L., R.E. Ziemer, D.E. Borth, 1985. Introduction to Spread Spectrum Communications. Prentice Hall.

[7] Williams, A. B. Electronic Filter Design Handbook. McGraw-Hill. 